\title{
Evaluation of Prognostic Factors and Survival Results in Geriatric Patients with Head and Neck Cancer
}

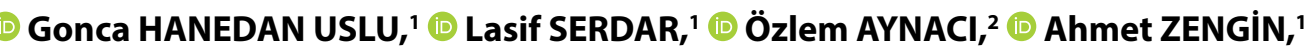 \\ (D) Emine CANYILMAZ² \\ 'Department of Radiation Oncology, Kanuni Training and Research Hospital, Trabzon-Turkey \\ ${ }^{2}$ Department of Radiation Oncology, Karadeniz Technical University Faculty of Medicine, Trabzon-Turkey
}

\begin{abstract}
OBJECTIVE
Length of life is gradually increasing along with the incidence of cancer in the elderly. Herein, we aimed to evaluate radiotherapy (RT) and chemoradiotherapy (CRT), surgical treatment (ST) results, clinicopathological features, and survival factors in patients $\geq 65$-years-old with head-and-neck cancer.
\end{abstract}

\section{METHODS}

We evaluated patients aged $\geq 65$ years with head-and-neck cancer who were treated in radiation oncology clinics in the Eastern Black Sea region of Turkey. After receiving the approval of the Ethics Committee, demographic, clinical, and histopathological data of the patients were obtained by reviewing their files and records.

\section{RESULTS}

Of 179 patients with head-and-neck cancer, 59 (33\%) were geriatric patients. Thirty-three patients were treated only with RT, 24 with CRT, and two with ST. The total RT dose ranged from 66 to $70 \mathrm{~Gy}$, and 40 $\mathrm{mg} / \mathrm{m}^{2}$ cisplatin could be weekly administered. While $50.8 \%$ of the patients had laryngeal cancer, $22 \%$ had oral cavity cancer. The mean follow-up period was 29.3 months; median overall survival (OS) was 27.5 months; 2 - and 5 -year OS were $56.6 \%$ and $32.2 \%$, respectively; median progression-free survival was 25.4 months. When prognostic factors that could affect general survival were analyzed in a univariate analysis, sex status $(\mathrm{p}=0.019)$ was found statistically significant. The most common side effect was Grade 3 mucositis (30\%).

\section{CONCLUSION}

Treatment modalities to be selected in elderly patients with head-and-neck cancer should be evaluated based on the performance status and not age. Elderly patients with no additional comorbidity can be treated with RT and/or CRT in a similar to that done in young patients.

Keywords: Elderly patients; head-and-neck cancer; radiotherapy.

Copyright $\odot$ 2022, Turkish Society for Radiation Oncology

\section{Introduction}

At over 65 years of age, cancer incidence accounts for 2163.9/100.000 cases.[1] Cancer is primarily a disease of the elderly, and $>60 \%$ of all patients with cancer are estimated to be $>65$ years of age.[2] As the global population continues to age, the number of elderly patients with cancer is expected to substantially increase. Over the next 20 years, there is expected to be a $67 \%$ increase in the cancer incidence among older adults.[3] Despite 
this projected rise in incidence, there are few data to guide clinicians with the optimal methods to treat older patients who are often diagnosed at higher stages, offered less aggressive therapy, and poorly accrued on prospective clinical trials and who have significant comorbidities. [4-6] With advancing age, functions of multiple organ systems decline, and other medical problems may develop.[2] These issues and perceived experience have led many clinicians to assume that older patients have less tolerance for and higher toxicity from radiation therapy (RT).[7] A previous study contradicts this; depending on the treated sites, RT is often believed to be well tolerated among older adults.[8] However, with the increasing number of older patients and increasing use of higher doses of RT and concurrent chemotherapy, it is important to systematically study acute and long-term toxicity in this population to understand what characteristics define the patient population that can and cannot tolerate aggressive RT regimens. Length of life is gradually increasing along with the incidence of cancer in elderly population. Herein, we aimed to evaluate RT and chemoradiotherapy (CRT) results, clinicopathological features, and survival factors in patients aged $\geq 65$ years with head-and-neck cancer.

\section{Materials and Methods}

Data were retrospectively collected from two existing radiation oncology clinics in the Eastern Black Sea region of Turkey. Patients aged over 65 years with headand-neck cancer admitted to our clinic for RT between 2011 and 2018 were evaluated. We obtained the demographic, clinical, and histopathological data of only 59 patients aged $\geq 65$ years. Stage of the disease was determined based on the 2010 International Union against Cancer/American Joint Committee on Cancer TNM classification. These patients were evaluated retrospectively and MRI, CT, and PET-CT were used for staging. The patients were able to complete RT and CRT treatments. We have never had a patient whose treatment has been decommissioned.

Radiotherapy schedules were applied at a dose of 1.8-2 Gy/day with a conventional fraction and of 66-70 Gy/week with five fractions. RT was planned and implemented with LINAC (6 or $18 \mathrm{MV}$ photon energy with the Eclipse planning system) and a TomoTherapy device using the IMRT technique. Further, a $40 \mathrm{mg} / \mathrm{m}^{2}$ cisplatin regimen was administered weekly, concurrently with chemotherapy. For data evaluation, suitability of variables to normal distribution was visually examined (histogram and probability plots) and by analytical methods (Kolmogorov-Smirnov tests). After examining the distribution of the variables, parametric interval data were examined using significance test of the difference between two means and Student's t-test, whereas nonparametric interval data were examined using the Mann-Whitney U-test; ordinal/nominal data were examined using the Chi-square analysis (or the Fisher's exact test for smaller samples). The Kaplan-Meier survival analysis was used to examine distribution of survival times, and log-rank test was performed to determine the difference between the survival times of the groups. For comparing the groups, Bonferroni correction was applied. Independent factors in predicting survival in multivariate analysis were examined using Cox regression analysis. When the type- 1 error level was $<5 \%$, the data were considered statistically significant. Statistical analyses were performed using SPSS version 13. Before the study, approval was obtained from the Ethics Committee of the Medical Faculty of Karadeniz Technical University to collect, evaluate, analyze, and interpret data.

\section{Results}

Among 179 patients with head-and-neck cancer, 59 (33\%) were geriatric patients, with 47 (79.7\%) male and $12(20.3 \%)$ female and a mean age of $72(65-86)$ years (Table 1 ).

The mean follow-up period was 29.3 (2.9-90.6) months. During follow-up, 34 (57.6\%) patients died, whereas 25 (42.4\%) were alive, with ongoing follow-up and treatment. During the follow-up, local relapse was observed in $2(3.4 \%)$ patients treated only by surgery, and these patients were treated with CRT. Metastasis was observed in 6 patients (10.2\%) during the followup, and the median time between diagnosis and RT was 3.3 (2.1-27.9) months.

The cancer sites among the patients included 30\% larynx, $13 \%$ oral cavity, $5 \%$ nasopharynx, $3 \%$ oropharynx, $3 \%$ hypopharynx, $3 \%$ salivary gland, and $2 \%$ paranasal sinus (Table 2).

When distributions were analyzed in terms of age and location, 65-74 years of age and laryngeal localization were most frequently observed (Fig. 1).

On univariate survival analysis, sex status $(\mathrm{p}=0.019)$ had a statistically significant effect on overall survival (OS) (Table 3).

Median OS was 27.5 months (95\% confidence interval [CI]: 16.7-38.3), whereas 2- and 5-year OS were $56.6 \% \pm 0.07 \%$ and $32.2 \% \pm 0.08 \%$, respectively (Fig. 2). 
Table 1 Patient characteristics

\begin{tabular}{|c|c|c|c|c|}
\hline Characteristics & Male & Female & Total & $\mathbf{p}$ \\
\hline The number of patients, (\%) & $47(79.7)$ & $12(20.3)$ & $59(100)$ & \\
\hline \multicolumn{5}{|l|}{ Age (year) } \\
\hline Median (range) & $71(65-86)$ & $78(67-86)$ & $72(65-86)$ & \multirow[t]{4}{*}{0.021} \\
\hline $65-74,(\%)$ & $32(68.1)$ & $5(41.7)$ & $37(62.7)$ & \\
\hline $75-84,(\%)$ & $14(29.8)$ & $5(41.7)$ & $19(32.2)$ & \\
\hline $85 \leq,(\%)$ & $1(2.1)$ & $2(16.7)$ & $3(5.1)$ & \\
\hline \multicolumn{5}{|l|}{ Location of primary tumor, (\%) } \\
\hline Nasopharynx & $2(4.3)$ & $3(25)$ & $5(8.5)$ & \multirow[t]{7}{*}{0.515} \\
\hline Larynx & $29(61.7)$ & $1(8.3)$ & $30(50.8)$ & \\
\hline Hypopharynx & $2(4.3)$ & $1(8.3)$ & $3(5.1)$ & \\
\hline Oral cavity & $7(14.9)$ & $6(50)$ & $13(22)$ & \\
\hline Oropharynx & $3(6.4)$ & - & $3(5.1)$ & \\
\hline Paranasal sinus & $1(2.1)$ & $1(8.3)$ & $2(3.4)$ & \\
\hline Salivary gland & $3(6.4)$ & - & $3(5.1)$ & \\
\hline \multicolumn{5}{|l|}{ Histology, $(\%)$} \\
\hline Squamous cell carcinoma & $40(85.1)$ & $8(66.7)$ & $48(81.4)$ & \multirow[t]{4}{*}{0.325} \\
\hline Adenocarcinoma & $3(6.4)$ & $1(8.3)$ & $4(6.8)$ & \\
\hline Undifferentiated carcinoma & $2(4.3)$ & $3(25)$ & $5(8.5)$ & \\
\hline Mucoepidermoid carcinoma & $2(4.3)$ & - & $2(3.4)$ & \\
\hline \multicolumn{5}{|l|}{ T stage, $(\%)$} \\
\hline $\mathrm{T} 1$ & $14(29.8)$ & $4(33.3)$ & $18(30.5)$ & \multirow[t]{4}{*}{0.961} \\
\hline $\mathrm{T} 2$ & $18(38.3)$ & $3(25)$ & $21(35.6)$ & \\
\hline T3 & $5(10.6)$ & $3(25)$ & $8(13.6)$ & \\
\hline $\mathrm{T} 4$ & $10(21.3)$ & $2(16.7)$ & $12(20.3)$ & \\
\hline \multicolumn{5}{|l|}{ Node status, (\%) } \\
\hline NO & $23(48.9)$ & $7(58.3)$ & $30(50.8)$ & \multirow[t]{4}{*}{0.559} \\
\hline N1 & $10(21.3)$ & $2(16.7)$ & $12(20.3)$ & \\
\hline N2 & $12(25.5)$ & $3(25)$ & $15(25.4)$ & \\
\hline N3 & $2(4.3)$ & - & $2(3.4)$ & \\
\hline \multicolumn{5}{|l|}{ Stage, $(\%)$} \\
\hline I & $12(25.5)$ & $3(25)$ & $15(25.4)$ & \multirow[t]{4}{*}{0.714} \\
\hline II & $6(12.8)$ & $2(16.7)$ & $8(13.6)$ & \\
\hline III & $9(19.1)$ & $3(25)$ & $12(20.3)$ & \\
\hline IV & $20(42.6)$ & $4(33.3)$ & $24(40.7)$ & \\
\hline \multicolumn{5}{|l|}{ Operation status, (\%) } \\
\hline Yes & $29(61.7)$ & $7(58.3)$ & $36(61)$ & \multirow[t]{2}{*}{0.832} \\
\hline No & $18(38.3)$ & $5(41.7)$ & $23(39)$ & \\
\hline \multicolumn{5}{|l|}{ Radiotherapy, (\%) } \\
\hline $\mathrm{RT}$ & $27(58.7)$ & $6(54.5)$ & $33(57.9)$ & \multirow[t]{2}{*}{0.804} \\
\hline CRT & $19(41.3)$ & $5(45.5)$ & $24(42.1)$ & \\
\hline \multicolumn{5}{|l|}{ RT device, (\%) } \\
\hline LINAC & $27(58.7)$ & $9(81.8)$ & $36(63.2)$ & \multirow[t]{2}{*}{0.185} \\
\hline TomoTherapy & $19(41.3)$ & $2(18.2)$ & $21(36.8)$ & \\
\hline \multicolumn{5}{|l|}{ RT dose, (\%) } \\
\hline$\leq 66$ & $23(50)$ & $7(63.6)$ & $30(52.6)$ & \multirow[t]{2}{*}{0.633} \\
\hline $66<$ & $23(50)$ & $4(36.4)$ & $27(47.4)$ & \\
\hline Treatment, (\%) & & & & \\
\hline ST & $1(2.1)$ & $1(8.3)$ & $2(3.4)$ & 0.506 \\
\hline RT & $15(31.9)$ & $2(16.7)$ & $17(28.8)$ & \\
\hline CRT & $3(6.4)$ & $3(25)$ & $6(10.2)$ & \\
\hline $\mathrm{ST}+\mathrm{RT}$ & $12(25.5)$ & $4(33.3)$ & $16(27.1)$ & \\
\hline $\mathrm{ST}+\mathrm{CRT}$ & $16(34)$ & $2(16.7)$ & $18(30.5)$ & \\
\hline
\end{tabular}




\begin{tabular}{|c|c|c|c|c|c|c|c|}
\hline Age & $\begin{array}{c}\text { Nasopharynx } \\
\text { (\%) }\end{array}$ & $\begin{array}{l}\text { Larynx } \\
(\%)\end{array}$ & $\begin{array}{l}\text { Hypopharynx } \\
\text { (\%) }\end{array}$ & $\begin{array}{c}\text { Oral cavity } \\
\text { (\%) }\end{array}$ & $\begin{array}{c}\text { Oropharynx } \\
\text { (\%) }\end{array}$ & $\begin{array}{c}\text { Paranasal sinus } \\
(\%)\end{array}$ & $\begin{array}{c}\text { Salivary gland } \\
\text { (\%) }\end{array}$ \\
\hline $65-74$ & $2(40)$ & $21(70)$ & $3(100)$ & $6(46.1)$ & $1(33.3)$ & $2(100)$ & $2(66.7)$ \\
\hline $75-84$ & $2(40)$ & $9(30)$ & - & $6(46.1)$ & $2(66.7)$ & - & - \\
\hline $85 \leq$ & $1(20)$ & - & - & $1(7.6)$ & - & - & $1(33.3)$ \\
\hline Total & 5 & 30 & 3 & 13 & 3 & 2 & 3 \\
\hline
\end{tabular}

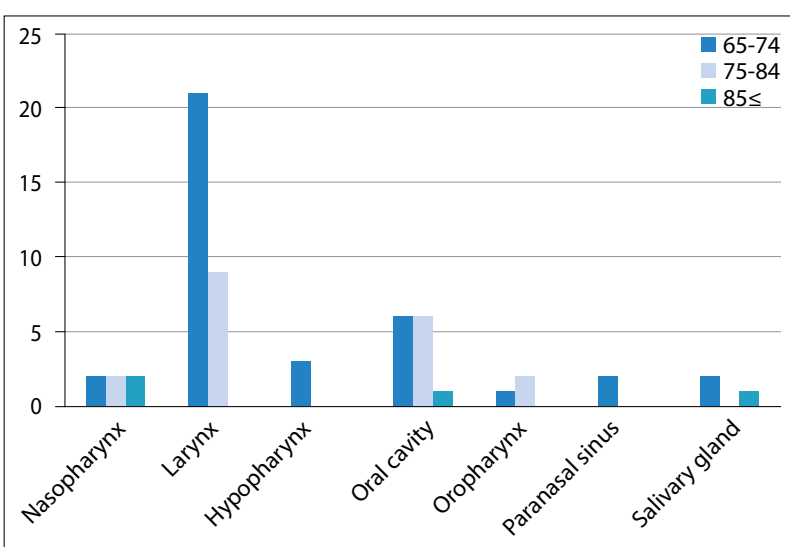

Fig. 1. Distribution of geriatric head-and-neck cancers based on age.

Median progression-free survival (PFS) was 25.4 months (95\% CI: 19.2-31.6), and 2- and 5-year PFS were found to be $50.8 \% \pm 0.07 \%$ and $30.5 \% \pm 0.08 \%$, respectively (Fig. 3).

On univariate analysis of factors associated with PFS, sex status $(\mathrm{p}=0.024)$ had a statistically significant effect on PFS (Table 4).

Overall, 18 patients $(30.5 \%)$ received post-operative CRT (ST+CRT), 17 (28.8\%) received only RT, $16(27.1 \%)$ received post-operative RT (ST+RT), 6 (10.2\%) received only CRT (CRT), and 2 (3.4\%) underwent only ST. Metastasis was observed in 6 patients (10.2\%) during the follow-up, and local relapse was observed in 2 (3.4\%) who only underwent ST. The patients with local relapse were treated with CRT.

On multivariate analysis, sex was the only prognostic factor that had a significant effect on OS and PFS $(\mathrm{p}=0.042$; Tables 5, 6).

RT was applied to 57 patients, of which 33 (57.9\%) and $24(42.1 \%)$ received only RT and CRT, respectively. In all RT patients, the most common side effects included weight loss (53 patients, 93\%), nausea and vomiting (46, 80\%), xerostomia (46, 80\%), Grades 1-2 skin reaction $(40,70 \%)$, and Grades $3-4$ mucositis $(18,31 \%)$.

\section{Discussion}

In the literature, elderly patients with head-and-neck cancer appear to constitute $24-46 \%$ of all patients with head-and-neck cancer.[9,10] At our clinic, 59 (33\%) of 179 patients diagnosed with head-and-neck cancer were $>65$ years of age, which is compatible with the available data. The National Institute of Aging uses three categories to describe elderly patients: $65-74$ (young-old), 75-84 (middle-old), and $\geq 85$ years (oldest-old).[11] Elderly patients are usually not included in clinical experimental studies, but are still considered based on data and estimates obtained in young patients. Cancers of the larynx, oropharynx, oral cavity, thyroid, and skin are the most common cancers in elderly patients. [12,13] In our series, $50.8 \%$ of the cases had laryngeal cancer and $22 \%$ had oral cavity cancer.

In the general population in Western countries, the extra life expectancy for a person aged 70 years is 14.2 years and for 85 years is 5.4 years.[14] In the United States, these periods are approximately 11 years for those aged $\geq 65$ years and 7 years for those aged 85 years. Quality of life is another factor to consider while determining treatment for patients with head-and-neck cancer.

Surgical treatment (ST) in patients with head-andneck cancer should be planned as is done for young patients if there is no additional comorbidity. In our study, 36 patients could be operated, and 27.5 months OS and 22.5 months PFS were observed. Chronological age should not be considered a limitation for neck dissection. ST should not be avoided in elderly patients with $\mathrm{N} 0$ neck who are at risk of regional spread. To reduce surgical mortality and morbidity among elderly patients, problems related to obesity, malnutrition, smoking, and alcohol should be corrected before surgery, careful sedation and analgesia should be performed, and caution should be exercised in fluid and blood transfusions, and operation time, that is, correction procedure should be short.[15] In a previous study, Clayman et al.[16] compared 43 patients aged $>80$ years and 79 aged $<65$ years, and showed that ma- 


\begin{tabular}{|c|c|c|c|}
\hline Variable & $\mathbf{n}$ & $\begin{array}{l}\text { Median survival } \\
\text { (months) }(95 \% \mathrm{Cl})\end{array}$ & $\mathbf{p}$ \\
\hline \multicolumn{4}{|l|}{ Age (year) } \\
\hline $65-74$ & 37 & $34.9(13.5-56.3)$ & 0.069 \\
\hline $75-84$ & 19 & $21.7(18.5-24.8)$ & \\
\hline $85 \leq$ & 3 & $14.8(0-33.8)$ & \\
\hline \multicolumn{4}{|l|}{ Sex } \\
\hline Male & 47 & $42.3(15.6-68.9)$ & 0.019 \\
\hline Female & 12 & $17.9(9.9-25.9)$ & \\
\hline \multicolumn{4}{|l|}{ Location of primary tumor } \\
\hline Nasopharynx & 5 & $23.6(9.7-37.5)$ & 0.359 \\
\hline Larynx & 30 & $47.6(34.7-60.5)$ & \\
\hline Hypopharynx & 3 & $26.1(0.2-52.1)$ & \\
\hline Oral cavity & 13 & $25.1(12.5-37.6)$ & \\
\hline Oropharynx & 3 & $45.9(23.8-68.1)$ & \\
\hline Paranasal sinus & 2 & $34.9(34.9-34.9)$ & \\
\hline Salivary gland & 3 & $42.3(42.3-42.3)$ & \\
\hline \multicolumn{4}{|l|}{ Histology } \\
\hline Squamous cell carcinoma & 48 & $42.8(32.8-52.8)$ & 0.980 \\
\hline Adenocarcinoma & 4 & $45.5(10.7-80.3)$ & \\
\hline Undifferentiated carcinoma & 5 & $23.6(9.7-37.1)$ & \\
\hline Mucoepidermoid carcinoma & 5 & $42.3(42.3-42.3)$ & \\
\hline \multicolumn{4}{|l|}{ T stage } \\
\hline $\mathrm{T} 1$ & 18 & $42.3(10-74.5)$ & 0.390 \\
\hline $\mathrm{T} 2$ & 21 & $27.5(14.7-40.3)$ & \\
\hline T3 & 8 & $34.9(18.5-51.3)$ & \\
\hline $\mathrm{T} 4$ & 12 & $21.7(8-35.3)$ & \\
\hline \multicolumn{4}{|l|}{ Node status } \\
\hline No & 30 & $27.5(11.4-43.7)$ & 0.127 \\
\hline N1 & 12 & $22.1(10.4-33.8)$ & \\
\hline N2 & 15 & $42.3(22.8-61.8)$ & \\
\hline N3 & 2 & $6.5(0-21.7)$ & \\
\hline \multicolumn{4}{|l|}{ Stage } \\
\hline 1 & 15 & $53.7(2.9-104.5)$ & 0.311 \\
\hline ॥ & 8 & $60.9(11.3-110.4)$ & \\
\hline III & 12 & $34.9(13.5-56.3)$ & \\
\hline IV & 24 & $27.5(19.9-35.1)$ & \\
\hline \multicolumn{4}{|l|}{ Operation status } \\
\hline Yes & 36 & $27.5(18.7-36.4)$ & 0.121 \\
\hline No & 23 & $53.7(6.2-101.1)$ & \\
\hline \multicolumn{4}{|l|}{ Radiotherapy } \\
\hline $\mathrm{RT}$ & 33 & $22.7(13.9-31.5)$ & 0.879 \\
\hline CRT & 24 & $29.2(26-32.3)$ & \\
\hline \multicolumn{4}{|l|}{ RT device } \\
\hline LINAC & 36 & $29.2(7-51.3)$ & 0.173 \\
\hline TomoTherapy & 21 & $27.5(15.4-39.6)$ & \\
\hline \multicolumn{4}{|l|}{ RT dose } \\
\hline$\leq 66$ & 30 & $29.2(21.1-37.3)$ & 0.769 \\
\hline$>66$ & 27 & $27.5(18.2-36.8)$ & \\
\hline \multicolumn{4}{|l|}{ Treatment } \\
\hline ST & 2 & $34.9(13-78)$ & 0.305 \\
\hline RT & 17 & $53.7(35-72)$ & \\
\hline CRT & 6 & $23.9(11.8-35.9)$ & \\
\hline $\mathrm{ST}+\mathrm{RT}$ & 16 & $21.7(13.3-30)$ & \\
\hline $\mathrm{ST}+\mathrm{CRT}$ & 18 & $29.2(24.8-33.5)$ & \\
\hline
\end{tabular}

$\mathrm{P}<0.05$ statistical significance. Cl: Confidence interval; RT: Radiotherapy; CRT: Chemoradiotherapy; ST: Surgical treatment; LINAC: Linear accelerator

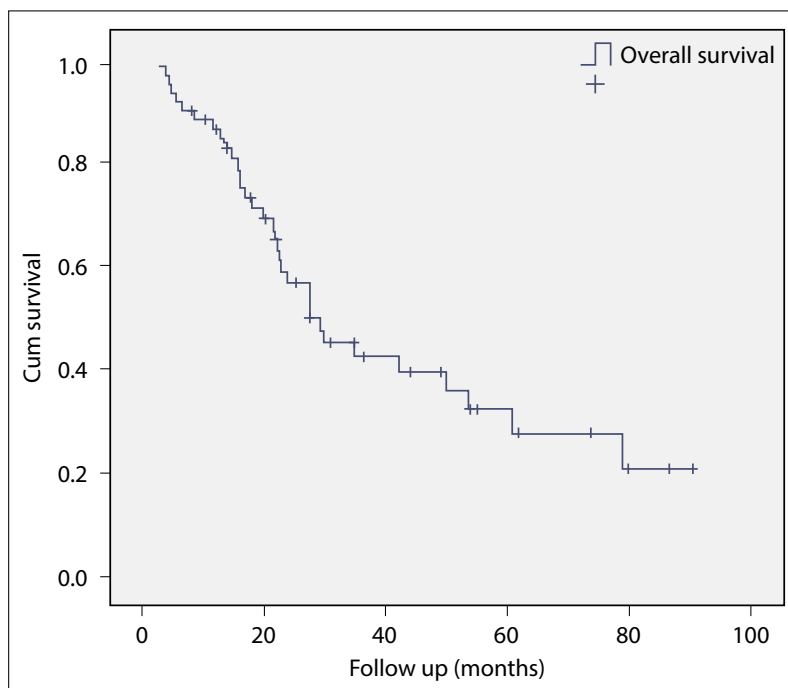

Fig. 2. Overall survival graph.

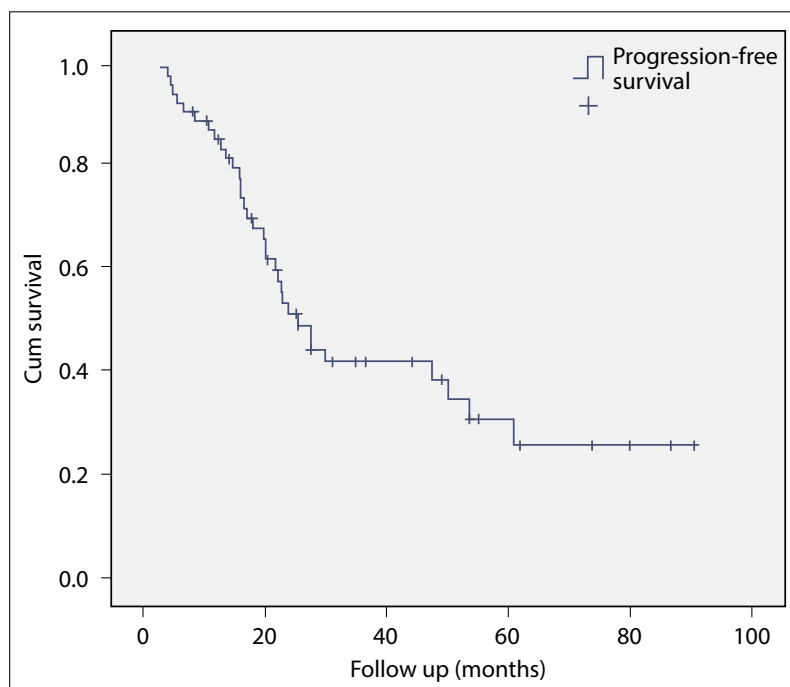

Fig. 3. Progression-free survival graph.

jor severe surgical procedures can be performed even in very old patients. Although the number of patients in the American Society of Anesthesiologists 3-4 was higher in the elderly group ( $93 \%$ vs. $63 \%$ ), the complications in both groups did not significantly differ. Cardiovascular and pulmonary complications were more prevalent in the elderly group, whereas local complications were noted in the young group. Further, mortality was not observed in the young group, and the mortality in the elderly group was found to be $2 \%$. When stage of the disease was considered, 2 and 5-year local control rates were similar in both the groups, and the mean survival rates were significantly lower in elderly patients. 


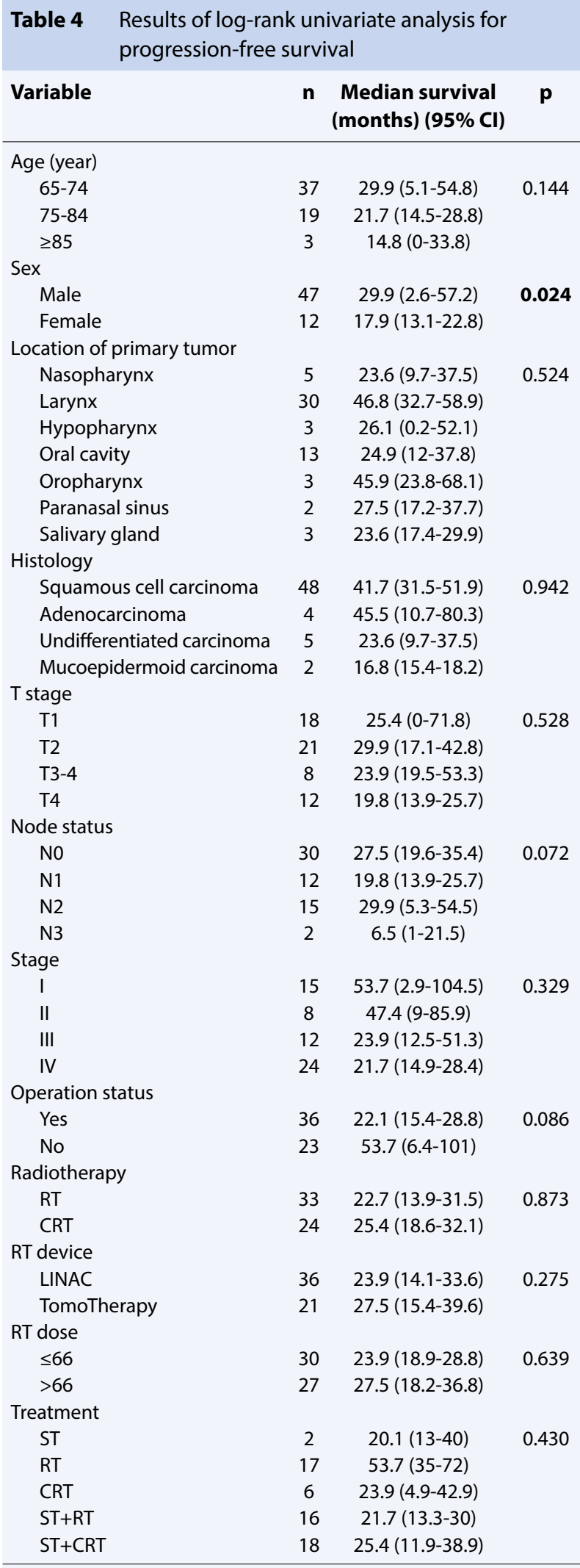

$\mathrm{P}<0.05$ statistical significance. Cl: Confidence interval; RT: Radiotherapy; CRT: Chemoradiotherapy; ST: Surgical treatment; LINAC: Linear accelerator
It would be correct to believe that there may be problems with elderly patients receiving 35 treatment sessions of conventional RT. Psychological problems, comorbid diseases, and immobilization difficulties are encountered during treatment.[15] Difficulties may also arise when 5-6-week RT with repeated daily doses is administered immediately after surgery. Further, there is an increase in non-curative treatments in RT treatments, which is often associated with accompanying health problems, failure to get patient's approval (46\%), and 3-year survival rates of $18 \%$ in elderly patients. There is a fear of increasing toxicity in the elderly.[17] The study that included the largest sample size was performed in the University of Florence in Italy. The results of 446 patients aged $>70$ years with cancers of the larynx, oral cavity, and oropharynx who underwent RT for treatment were compared with those of patients aged $<70$ years with the same type and stage of tumors. Notably, there was no difference between the 5-year local control and survival rates in the patients with cancers of the larynx and oropharynx, whereas better local control rate (50-28\%) was observed in younger patients with oral cavity cancer. Moreover, there was no statistically significant difference between disease-free survival rates.

Early and late reactions to RT in the elderly did not differ from those in younger patients. The most important parameters determining early and late side effects were modality and fractional scheme applied in the treatment plan. These side effects can be minimized using the IMRT technique.[18] In the present study, we treated all patients using the IMRT technique. In the study conducted by Zachariah et al.[19] on 35 patients with head-and-neck cancer at different regions and stages who were treated with radical RT (65.9 Gy), it was reported that $51 \%$ of these patients had mild (G1G2), $29 \%$ had moderate (G3), and only $3 \%$ had severe hemorrhagic (G4) mucositis. The objective response rate in the patients was $86 \%$ and complete remission rate was $66 \%$. In patients with complete remission, the longest survival period was 25 months. In the present study, RT was applied to 57 patients, and $57.9 \%$ received conventional curative RT while $42.1 \%$ received CRT. In $31 \%$ of the patients, moderate-to-severe mucositis developed, which was consistent with that reported in the literature. Accelerated RT and hyperfractional RT are applications avoided in elderly patients because of increased toxicity observed even in young patients. In a similar study, it was reported that in $8 \%$ of patients aged $>70$ years with cancers of the hypopharynx, larynx, oral cavity, and oropharynx cancer, treatment should 
Table 5 Results of the multivariate analysis for overall survival by Cox proportional hazard model

\begin{tabular}{lccc} 
Variable & Variable classification & Hazard ratio (95\% Cl) & $\mathbf{p}$ \\
\hline Sex & Male vs. female & $2.5(1-5.9)$ & $\mathbf{0 . 0 4 2}$ \\
Age (year) & $65-74$ vs. 75-84 & $1.3(0.6-2.9)$ & 0.209 \\
& $65-74$ vs. $85 \leq$ & $4.8(0.8-27.6)$ & 0.510 \\
& & & 0.079 \\
T stage & T1-2 vs. T3-4 & $0.9(0.4-2.3)$ & 0.883 \\
Node status & No vs. N+ & $0.7(0.2-1.9)$ & 0.467 \\
Stage & I-II and III & $0.9(0.2-3.6)$ & 0.161 \\
& I-II and IV & $2.5(0.7-9)$ & 0.899 \\
Operation status & & & 0.148 \\
\hline
\end{tabular}

$\mathrm{P}<0.05$ statistical significance. $\mathrm{Cl}$ : Confidence interval; vs.: Versus

Table 6 Results of the multivariate analysis for progression-free survival by Cox proportional hazard model

\begin{tabular}{lccr} 
Variable & Variable classification & Hazard ratio (95\% Cl) & $\mathbf{p}$ \\
\hline Sex & Male vs. female & $2.4(1.1-5.9)$ & $\mathbf{0 . 0 4 6}$ \\
Age (year) & $65-74$ vs. 75-84 & $1.1(0.5-2.4)$ & 0.351 \\
& $65-74$ vs. $85 \leq$ & $3.5(0.6-19.8)$ & 0.829 \\
& & & 0.151 \\
T stage & T1-2 vs. T3-4 & $0.9(0.4-2.5)$ & 0.956 \\
Node status & N0 vs. N+ & $0.8(0.3-2.3)$ & 0.667 \\
Stage & I-II and III & $0.7(0.2-2.8)$ & 0.244 \\
& I-II and IV & $1.9(0.5-6.6)$ & 0.609 \\
Operation status & & & 0.340 \\
\hline
\end{tabular}

$\mathrm{P}<0.05$ statistical significance. $\mathrm{Cl}$ : Confidence interval, vs.: Versus

be terminated.[20] Even with conventional external applications, RT seems to be an appropriate treatment with non-conventional treatments for elderly patients with head-and-neck cancer. At radical doses, there is a locoregional response in the elderly, which is equally as good as the response observed in younger patients with the same type of tumor. It should be considered that there is a similarity in terms of acute and late toxicity of RT and that there may be considerable reductions in the ability to withstand subjective tolerance and sometimes curability in the elderly.[16]

\section{Conclusion}

Patients with head-and-neck cancer aged 65 years or older can be treated in a similar manner to young patients with chemotherapy, CRT, or ST. With the help of more series of patients and homogeneous distribution, studies with large series can be done to determine the best treatment modality for this age group.
Peer-review: Externally peer-reviewed.

Conflict of Interest: All authors declared no conflict of interest.

Ethics Committee Approval: The study was approved by the Karadeniz Technical University Faculty of Medicine Scientific Research Ethics Committee (No: 2017/133, Date: 02/03/2018).

Financial Support: This study has received no financial support.

Authorship contributions: Concept - G.H.U.; Design G.H.U.; Supervision - G.H.U., Ö.A.; Funding - G.H.U., L.S.; Materials - G.H.U., L.S.; Data collection and/or processing - G.H.U., E.C.; Data analysis and/or interpretation - G.H.U., L.S.; Literature search - G.H.U., A.Z.; Writing - G.H.U.; Critical review - E.C.

\section{References}

1. Ramesh HS, Pope D, Gennari R, Audisio RA. Optimizing surgical management of elderly cancer patients. World J Surg Oncol 2005;3(1):17. 
2. Balducci L, Lyman GH, Ershler WB, Extermann M. Comprehensive Geriatric Oncology. $2^{\text {nd }}$ ed. Boca Raton, FL: Taylor \& Francis Group; 2004. p. 1267-79.

3. Smith BD, Smith GL, Hurria A, Hortobagyi GN, Buchholz TA. Future of cancer incidence in the United States: Burdens upon an aging, changing nation. J Clin Oncol 2009;27(17):2758-65.

4. de Rijke JM, Schouten LJ, Schouten HC, Jager JJ, Koppejan AG, van den Brandt PA. Age-specific differences in the diagnosis and treatment of cancer patients aged 50 years and older in the province of Limburg, The Netherlands. Ann Oncol 1996;7(7):677-85.

5. Fentiman IS, Tirelli U, Monfardini S, Schneider M, Festen J, Cognetti F, et al. Cancer in the elderly: Why so badly treated? Lancet 1990;335(8696):1020-2.

6. Talarico L, Chen G, Pazdur R. Enrollment of elderly patients in clinical trials for cancer drug registration: A 7-year experience by the US food and drug administration. J Clin Oncol 2004;22(22):4626-31.

7. Gunn WG. Radiation therapy for the aging patient. CA Cancer J Clin 1980;30(6):337-47.

8. Olmi P, Ausili-Cefaro G. Radiotherapy in the elderly: A multicentric prospective study on 2060 patients referred to 37 Italian radiation therapy centers. Rays 1997;22 Suppl 1:53-6.

9. Metges JP, Eschwege F, de Crevoisier R, Lusinchi A, Bourhis J, Wibault P. Radiotherapy in head and neck cancer in the elderly: A challenge. Crit Rev Oncol Hematol 2000;34(3):195-203.

10. Hirano M, Mori K. Management of cancer in the elderly: Therapeutic dilemmas. Otolaryngol Head Neck Surg 1998;118(1):110-4.

11. Kennedy BJ. Aging and cancer. J Clin Oncol 1988;6(12):1903-11.
12. Gourin CG, McAfee WJ, Neyman KM, Howington JW, Podolsky RH, Terris DJ. Effect of comorbidity on the quality of life and treatment in patients with squamous cell carcinoma of the head and neck. Laryngoscope 2005;115(8):1371-5.

13. Sanabria A, Carvalho AL, Vartanian JG, Magrin J, Ikeda MK, Kowalski LP. Comorbidity is a prognostic factor in elderly patients with head and neck cancer. Ann Surg Oncol 2007;14(4):1449-57.

14. Yancik R, Ries LA. Cancer in older persons. Magnitude of the problem-how do we apply what we know? Cancer 1994;74 Suppl 7:1995-2003.

15. Güney E, Çağlı S, Yüce İ. Head and neck cancers in geriatric patients. Kulak Burun Bogaz Ihtis Derg 2009;19(1):45-54.

16. Clayman GL, Eicher SA, Sicard MW, Razmpa E, Goepfert H. Surgical outcomes in head and neck cancer patients 80 years of age and older. Head Neck 1998;20(3):216-23.

17. Baumann $M$. Is curative radiation therapy in elderly patients limited by increased normal tissue toxicity? Radiother Oncol 1998;46(3):225-7.

18. Ampil FL, Mills GM, Stucker FJ, Burton GV, Nathan CO. Radical combined treatment of locally extensive head and neck cancer in the elderly. Am J Otolaryngol 2001;22(1):65-9.

19. Zachariah B, Balducci L, Venkattaramanabalaji GV, Casey L, Greenberg HM, DelRegato JA. Radiotherapy for cancer patients aged 80 and older: A study of effectiveness and side effects. Int J Radiat Oncol Biol Phys 1997;39(5):1125-9.

20. Allal AS, Maire D, Becker M, Dulguerov P. Feasibility and early results of radiotherapy for head and neck carcinoma in the elderly. Cancer 2000;88(3):648-52. 